\title{
Does acellular dermal matrix expand in response to tissue expander inflation?
}

\author{
Chae Eun Yang, Kwang Hyun Park, Dong Won Lee, Dae Hyun Lew, Seung Yong Song \\ Department of Plastic and Reconstructive Surgery, Institute for Human Tissue Restoration, Yonsei University College of Medicine, Seoul, Korea
}

Background Acellular dermal matrices (ADMs) have recently become widely used in breast reconstruction, but the correlation between the final expander volume and the surface area of the ADM is not well understood. In this study, the expansion of the surface area of ADM and the expander volume was studied retrospectively in cases of acellular dermis-assisted tissue expander breast reconstruction.

Methods Twenty cases of immediate breast reconstruction using an ADM-assisted tissue expander from January 2015 to December 2015 were evaluated. In all 20 cases, CGCryoDerm was used as the matrix, with a thickness of 1-3 mm. No slit incisions were made. Finally, the proportional increase in the area of the fully expanded ADM was compared to that of the tissue expander volume.

Results The proportional increase in the ADM surface area was calculated to be from 1.1 to 2.46 , with a mean value of 1.7. Additionally, under the assumption that the expander had a spherical shape, the increase in its radius (the cube root of its volume) was assessed. The range of the proportional increase in the expander radius was 1.1 to 2.24 , with a mean value of 1.66. The proportional increase in the radius of the expanded ADM surface area ranged from 1.04 to 1.34 , with a mean ratio of 1.28 .

Conclusions The results of this study confirmed that the ADM expanded when the tissue expander was inflated. However, the ADM expanded to a lesser extent than the tissue expander, indicating that the muscle and other tissues expanded more than the ADM when the tissue expander was inflated.

Keywords Acellular dermis / Mammaplasty / Tissue expansion
Correspondence: Seung Yong Song Department of Plastic and Reconstructive Surgery, Institute for Human Tissue Restoration, Yonsei University College of Medicine, 50-1 Yonsei-ro, Seodaemun-gu, Seoul 03722, Korea

Tel: $+82-2-2228-2210$

Fax: +82-2-393-6947

E-mail: pssysong@yuhs.ac

The authors thank Mr. Dong-Su Jang, Research Assistant, Department of Anatomy, Yonsei University College of Medicine, Seoul, Korea, for help with the figures.

Received: 12 Apr 2018 • Revised: 9 Jul 2018 • Accepted: 13 Aug 2018

pISSN: 2234-6163 • elSSN: 2234-6171 • https://doi.org/10.5999/aps.2018.00304 • Arch Plast Surg 2019;46:34-38

\section{INTRODUCTION}

In the United States, it is estimated that $76 \%$ of all immediate breast reconstructions involve implants, either through direct implantation or via tissue expansion. However, breasts that are reconstructed using implants tend to be less natural and ptotic. In addition, the lack of soft tissue and muscle coverage at the lateral and inferior poles is a disadvantage of this method of recon- struction $[1,2]$. Therefore, during the early period of implantbased breast reconstruction, a dual-plane technique was used in which the implant was set under the pectoralis major muscle and the latero-inferior aspects of the implant were covered with a mastectomy flap $[3,4]$. However, the dual-plane technique is limited by challenges in recreation of the inframammary fold, displacement during expansion, and poor coverage of the lower pole [5]. 
Acellular dermal matrix (ADM) has been used in immediate implant-based breast reconstruction since approximately 2005, after a case report described its use as a sling to cover the inferolateral pole [6]. This procedure has three main benefits: improved lower pole projection, satisfactory recreation of the inframammary fold, and complete implant coverage. These advantages enable greater initial tissue expansion [1,3,5,7-9]. Based on these advantages, surgeons often elect to use ADM for tissue expander- or implant-based reconstruction. As the application of this approach increases, some surgeons are beginning to wonder how much the $\mathrm{ADM}$ expands during the inflation process, because predicting and understanding the expandability of grafted $\mathrm{ADM}$ will help to improve the results of breast reconstruction.

In our department, we have measured the extent of ADM expansion in the second stage of reconstructions since 2015. In the present study, we analyzed the relationship between the final expander volume and the extent of ADM expansion.

\section{METHODS}

A retrospective chart review was conducted of mastectomies performed between January 2015 and December 2015 at the Department of Plastic and Reconstructive Surgery of Severance Hospital. All patients undergoing immediate 2-stage breast reconstruction including an $\mathrm{ADM}$ sling were eligible. Twenty cases of reconstruction in 19 patients were included in this study. No slit incisions were made on the ADM. In all 20 cases, CGCryoDerm (CG BIO Corp., Seongnam, Korea) was used as the $\mathrm{ADM}$, with a thickness of 1 to $3 \mathrm{~mm}$. The exact sizes of the CGCryoDerm are presented in Table 1. We used Natrelle Style 133 (Allergan, Inc., Irvine, CA, USA) tissue expanders. Detailed information on the tissue expanders used is presented in Table 2.

\section{Surgical technique}

All procedures utilized the pectoralis major muscle and an

\section{Table 1. Summary of the dimensions of CGCryoDerm}

\begin{tabular}{|lc|}
\hline Size $(\mathrm{cm})$ & Number \\
\hline $4 \times 15$ & 3 \\
$4 \times 16$ & 2 \\
$4 \times 17$ & 1 \\
$5 \times 12$ & 2 \\
$5 \times 14$ & 3 \\
$5 \times 15$ & 4 \\
$6 \times 12$ & 2 \\
$6 \times 14$ & 1 \\
$6 \times 15$ & 1 \\
$6 \times 17$ & 1 \\
Total & 20 \\
\hline
\end{tabular}

ADM sling. A tissue expander was placed into the subpectoralis plane. We elevated the pectoralis major muscle to create an appropriately sized pocket and then secured the ADM to the pectoralis major superiorly and the chest wall latero-inferiorly. A new Inframammary fold was defined by the ADM fixation. The tissue expander was inflated with up to $100 \mathrm{~mL}$ of distilled water depending on the patient's anatomical characteristics and the incision was closed. After sufficient expansion was obtained, the patient underwent a second operation to inset the permanent breast implant.

\section{Measurement and analysis}

The area of the $\mathrm{ADM}$ was measured during the second breast reconstruction operation when the tissue expander was replaced with a permanent breast implant. We marked the four edges of the expanded ADM and drew a square with four edges. The width and length of the square were measured and the area of the square, which represented the extent of the expanded ADM, was calculated. We also measured the amount of distilled water in the inflated expander, which indicated the final volume of the tissue expander (Fig. 1).

Under the assumption that the tissue expander was round, the extent of the expanded $\mathrm{ADM}$ was proportional to the square of its radius and the expanded volume of the tissue expander was proportional to the cube of its radius. We calculated the radius from the volume of the expander and the surface area of the $\mathrm{ADM}$ preoperatively and postoperatively. The cube root of the expander volume was defined as the radius of volume $\left(r_{v}\right)$ and the square root of the ADM surface area was defined as the radius of extent $\left(\mathrm{r}_{\mathrm{e}}\right)$. We compared the proportional increase in the radius of the expander volume and the $\mathrm{ADM}$ area. All analyses were performed using Excel (Microsoft Corp., Redmond, WA, USA) (Fig. 2).

\section{Table 2. Summary of the tissue expanders used}

\begin{tabular}{|lc|}
\hline Type & Number \\
\hline 133FV11 & 1 \\
133FV12 & 4 \\
133FV13 & 9 \\
133FV14 & 1 \\
133MV12 & 1 \\
133MV13 & 4 \\
Total & 20 \\
\hline N-67-133FV11: $300 \mathrm{~cm}^{3}, 11 \times 11.5 \times 5($ width $[\mathrm{cm}] \times$ height [cm] $) \times$ projection \\
[cm]); N-67-133FV12: $400 \mathrm{~cm}^{3}, 12 \times 12.5 \times 5.3 ; \mathrm{N}-67-133 F V 13: 500 \mathrm{~cm}^{3}$, \\
13 $\times 13.5 \times 5.7 ; \mathrm{N}-67-133 \mathrm{FV} 14: 600 \mathrm{~cm}^{3}, 14 \times 14.5 \times 6.2 ; \mathrm{N}-67-133 \mathrm{MV} 12:$ \\
$300 \mathrm{~cm}^{3}, 12 \times 11 \times 5.2 ;$ N-67-133MV13: $400 \mathrm{~cm}^{3}, 13 \times 12 \times 5.6$. \\
FV, full height/variable projection; MV, moderate height/variable projection. \\
\hline
\end{tabular}




\section{RESULTS}

A total of 19 patients with 20 reconstructions using CGcryoDerm in 20 breasts were included in this study. We evaluated the preoperative ADM extent and tissue expander volume. There were no complications, including seroma, infection, or hemato$\mathrm{ma}$, in the enrolled patients. We defined the preoperative tissue expander volume as the amount of intraoperative inflation. Measurements after the final expansion were performed using the same methods. The initial average $\mathrm{ADM}$ area was $70.3 \mathrm{~cm}^{2}$

Fig. 1. Measurements of ADM area

$(A-C)$ The acellular dermal matrix (ADM) that was used. There was no folding or thinning of the ADM.
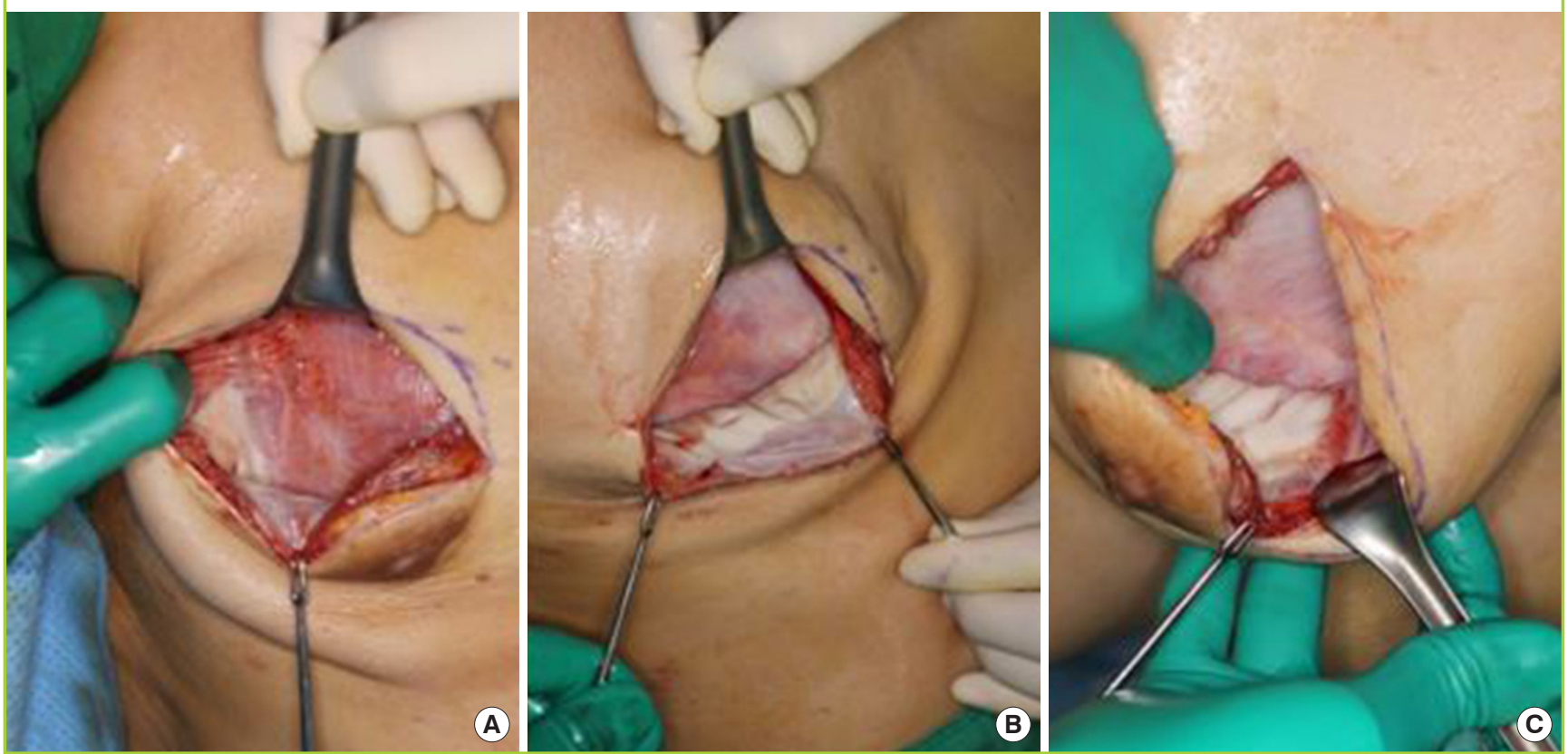

Fig. 2. Tissue expander with an ADM sling

Assuming that the tissue expander was round, we hypothesized that $r_{e}$ (the radius of the acellular dermal matrix [ADM] area) and $r_{v}$ (radius of the tissue expander volume) would be equal. $r_{e}$ and $r_{v}$ had equal dimensions, making it possible to compare them directly. (A) Conceptual image of round tissue expander and ADM. (B) Schema of how the proportional increases were compared.
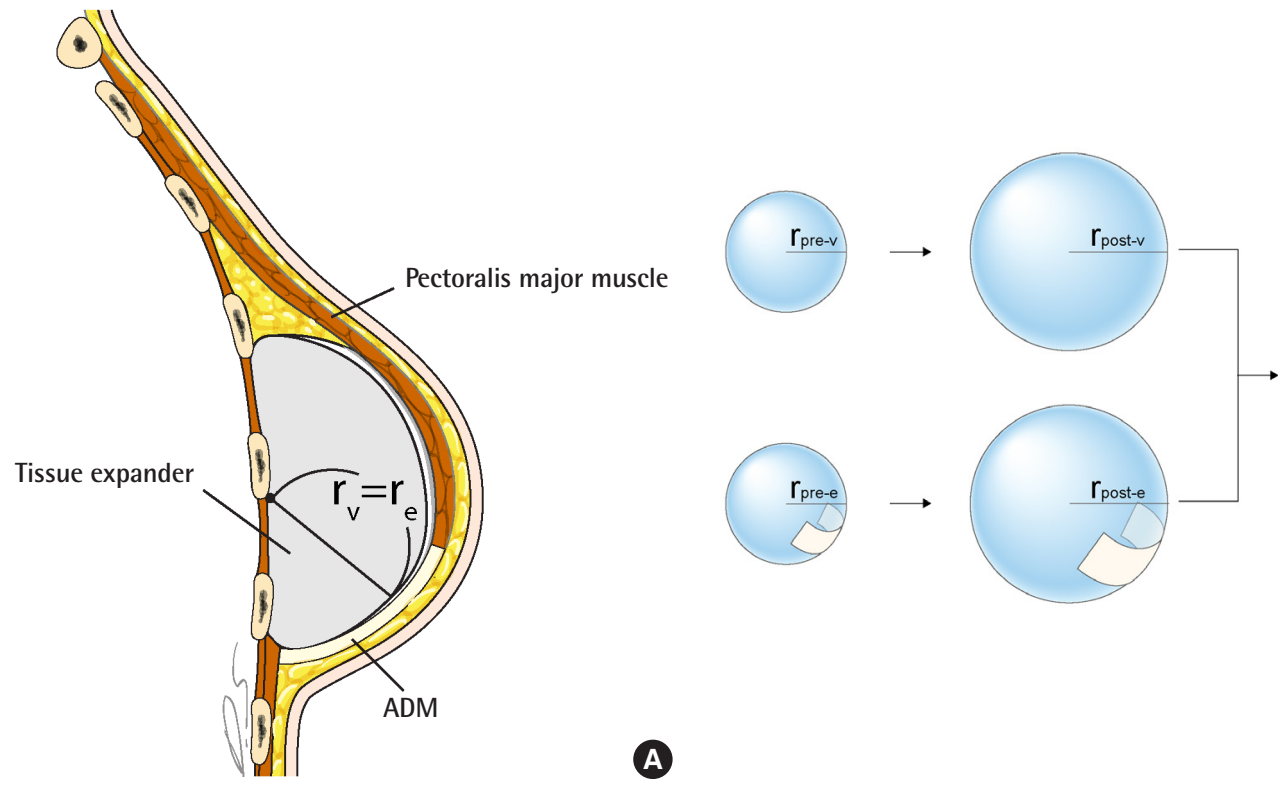

Comparison of ratio

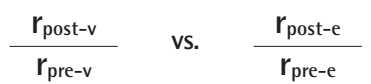


(range, 60-102 $\mathrm{cm}^{2}$ ) and the average tissue expander volume was $116 \mathrm{~mL}$ (range, 30-300 mL). The average final expanded $\mathrm{ADM}$ area was $118.7 \mathrm{~cm}^{2}$ (range, $65-185 \mathrm{~cm}^{2}$ ) and the average final volume was $402.5 \mathrm{~mL}$ (range, $250-550 \mathrm{~mL}$ ) (Table 3).

We calculated the radius using the square root of the $\mathrm{ADM}$ surface area preoperatively and postoperatively. The average preoperative radius of the $\mathrm{ADM}$ extent $\left(\mathrm{r}_{\mathrm{e}}\right)$ was $8.36 \mathrm{~cm}$ (range, $7.74-10 \mathrm{~cm}$ ). The average postoperative $\mathrm{r}_{\mathrm{e}}$ was $10.8 \mathrm{~cm}$ (range, $8.06-13.6 \mathrm{~cm}$ ). We also calculated the radius from the cube root of the volume of the tissue expander preoperatively and postoperatively. The average preoperative expander radius $\left(r_{v}\right)$ was 4.62 $\mathrm{cm}$ (range, 3.1-6.69 cm). The average postoperative $r_{v}$ was 7.34 $\mathrm{cm}$ (range, 6.12-8.2 cm) (Table 4).

Based on these results, we compared the proportional increases in the radius values. The proportional increase in the radius of the ADM surface area ranged from 1.04 to 1.34 (mean, 1.28) and that of the radius of expander volume ranged from 1.1 to

\section{Table 3. Summary of tissue expander volume and ADM area}

\begin{tabular}{|lcc|}
\hline & $\begin{array}{c}\text { Tissue expander } \\
(\mathbf{m L})\end{array}$ & $\begin{array}{c}\text { ADM } \\
\left(\mathbf{c m}^{2}\right)\end{array}$ \\
\hline $\begin{array}{l}\text { Measurements in the initial } \\
\text { state }\end{array}$ & $116(30-300)$ & $70.3(60-102)$ \\
$\begin{array}{l}\text { Measurements after final } \\
\text { expansion }\end{array}$ & $402.5(250-550)$ & $118.7(65-185)$ \\
\hline $\begin{array}{l}\text { Values are presented as average (range). } \\
\text { ADM, acellular dermal matrix. }\end{array}$ & \\
\hline
\end{tabular}

\section{Table 4. Preoperative and postoperative calculated radif}

\begin{tabular}{|c|c|c|}
\hline & $\begin{array}{l}\text { Tissue expander } \\
\text { volume }\end{array}$ & ADM area \\
\hline $\begin{array}{l}\text { Preoperative calculated radius } \\
\left(r_{\text {pre-v }} \& r_{\text {pre-e, }}, \mathrm{cm}\right)\end{array}$ & $4.62(3.1-6.69)$ & $8.36(7.74-10)$ \\
\hline 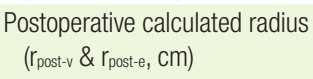 & $7.34(6.12-8.2)$ & $10.8(8.06-13.6)$ \\
\hline \multicolumn{3}{|c|}{$\begin{array}{l}\text { Values are presented as average (range). } \\
\text { ADM, acellular dermal matrix; } r_{e} \text {, radius of ADM area; } r_{v} \text {, radius of the tissue } \\
\text { expander volume. }\end{array}$} \\
\hline
\end{tabular}

Table 5. Comparison of the proportional increase in the radii for ADM area and expander volume

\begin{tabular}{|lcc|}
\hline & Tissue expander & ADM \\
\hline Proportional increase in the ratio & $1.1-2.24$ & $1.04-1.34$ \\
$\begin{array}{l}\text { Mean value of the proportional } \\
\text { increase }\end{array}$ & 1.66 & 1.28 \\
\hline
\end{tabular}

We compared the proportional increase in the radius, assuming that the tissue expander was round. We calculated the proportional increase and the mean value thereof. We predicted that the proportional increases would be the same, but the proportional increase in the tissue expander radius was greater than that of the acellular dermal matrix (ADM) radius.

\subsection{4 (mean, 1.66) (Table 5).}

We hypothesized that the increase in $r_{e}$ and $r_{v}$ would be equal, assuming the tissue expander to be round. However, we found that the proportional increase of $r_{v}$ was greater than that of $r_{e}$. We confirmed that the ADM expanded when the tissue expander was inflated and that the expansion of the ADM surface area was less than the expansion of the tissue expander volume. Based on these findings, we suggest that other surrounding tissues, such as muscles, expand to a greater extent than the ADM when the tissue expander is inflated.

\section{DISCUSSION}

The aim of this study was to confirm whether ADM expanded along with tissue inflation in 2-stage breast reconstruction. We observed the expected expansion of ADM in response to inflation, and further examined whether the proportional expansion of $\mathrm{ADM}$ was equal to the proportional expansion of the expander's radius, based on the hypothesis that the same radius value can be used when the area of a circle and the volume of a sphere are measured. Although the tissue expander was anatomically shaped, we assumed that it was round for the analyses in this study. Because ADM adheres to the bottom of the expander during the procedure, we theorized that the radii of the ADM and the expander would be the same. Since the expander was assumed to be round, there were some differences when compared to the actual values, but the overall trend was the primary focus of this study. Our data confirmed that the increase in $\mathrm{ADM}$ was significantly smaller than the increase in expander size. This is thought to have been due to greater expansion of nearby muscles, such as the pectoralis major, and greater tension caused by thickening of the skin with the adhesion of ADM to the layers. Even with an anatomically-shaped tissue expander, the actual maximum extension force may be concentrated at the center of the expander due to skin tension, which may cause greater muscle expansion than ADM expansion. However, in this study, we only used CGCryoDerm. This material may not be representative of all $\mathrm{ADMs}$, so several kinds of ADMs should be investigated in further studies. In addition, the recently developed prehydrated ADM is softer; the present study did not assess this type of ADM, although it has been suggested that prehydrated ADM may show a different pattern of expansion.

Although ADM slings are widely used in implant-based breast reconstruction, the mechanical characteristics of tissue expansion have not been analyzed in previous studies. This study is significant as the first analysis of this issue. Since the expansion of $\mathrm{ADM}$ is insufficient compared to the expansion of other tissues in 2-stage breast reconstruction, it is advantageous to use a suffi- 
cient amount of $\mathrm{ADM}$ from the beginning. When a patient's breast requires large-volume expansion, the use of a large amount of $\mathrm{ADM}$ can be considered. Based on the findings of the present study, the expansion potential of ADM is relatively small compared to that of human tissue. Surgeons should therefore consider using a large $\mathrm{ADM}$ and making slit incisions on the $\mathrm{ADM}$.

Recently, prepectoral implant insertion has received much attention. In these circumstances, prepectoral tissue expander insertion is also attempted. Unlike subpectoral insertion, prepectoral tissue expander insertion requires complete coverage with $\mathrm{ADM}[10]$. Based on this study, we predict that use of a tissue expander in the prepectoral pocket will not be easy in comparison to expansion in the subpectoral pocket. The authors think that multiple slit incisions will be necessary to improve expansion.

In addition, nipple up-riding is a difficult problem to solve in implant-based reconstruction in patients who undergo nipplesparing mastectomy [11]. Because the final expansion amount of $\mathrm{ADM}$ is small relative to the expansion of other tissues, anchoring the nipple base to the ADM with absorbable sutures at the proper position of the lower pole $\mathrm{ADM}$ will help to prevent upward migration of the nipple.

This study was designed to answer the common question of whether $\mathrm{ADM}$ slings used in breast reconstruction surgery actually expand properly, as expected. The results show that the ADM did not expand to the same extent as the expander, and that most of the $\mathrm{ADM}$ was located in the lower pole of the expander where the breast was reconstructed. Thus, it can be assumed that more soft tissue will be recruited in patients to compensate for the relatively limited expansion potential of ADM located in the lower pole, especially during the early period of expansion.

\section{NOTES}

\section{Conflict of interest}

No potential conflict of interest relevant to this article was reported.

\section{Ethical approval}

The study was approved by the Institutional Review Board of Severance Hospital (IRB No. 4-2017-1173) and performed in accordance with the principles of the Declaration of Helsinki. Written informed consents were waived.

\section{Patient consent}

The patients provided written informed consent for the publication and the use of their images.

\section{ORCID}

Chae Eun Yang https://orcid.org/0000-0001-8128-791X

Kwang Hyun Park https://orcid.org/0000-0002-5856-3928

Dong Won Lee https://orcid.org/0000-0003-0046-3139

Dae Hyun Lew https://orcid.org/0000-0002-2625-5664

Seung Yong Song https://orcid.org/0000-0002-3145-7463

\section{REFERENCES}

1. Chun YS, Verma K, Rosen H, et al. Implant-based breast reconstruction using acellular dermal matrix and the risk of postoperative complications. Plast Reconstr Surg 2010;125: 429-36.

2. Warren AG, Morris DJ, Houlihan MJ, et al. Breast reconstruction in a changing breast cancer treatment paradigm. Plast Reconstr Surg 2008;121:1116-26.

3. Weichman KE, Wilson SC, Weinstein AL, et al. The use of acellular dermal matrix in immediate two-stage tissue expander breast reconstruction. Plast Reconstr Surg 2012;129: 1049-58.

4. Zienowicz RJ, Karacaoglu E. Implant-based breast reconstruction with allograft. Plast Reconstr Surg 2007;120:37381.

5. Hanna KR, DeGeorge BR Jr, Mericli AF, et al. Comparison study oftwo types of expander-based breast reconstruction: acellular dermal matrix-assisted versus total submuscular placement. Ann Plast Surg 2013;70:10-5.

6. Breuing KH, Warren SM. Immediate bilateral breast reconstruction with implants and inferolateral AlloDerm slings. Ann Plast Surg 2005;55:232-9.

7. Sbitany H, Sandeen SN, Amalfi AN, et al. Acellular dermisassisted prosthetic breast reconstruction versus complete submuscular coverage: a head-to-head comparison of outcomes. Plast Reconstr Surg 2009;124:1735-40.

8. Gamboa-Bobadilla GM. Implant breast reconstruction using acellular dermal matrix. Ann Plast Surg 2006;56:22-5.

9. Davila AA, Seth AK, Wang E, et al. Human acellular dermis versus submuscular tissue expander breast reconstruction: a multivariate analysis of short-term complications. Arch Plast Surg 2013;40:19-27.

10. Sbitany H, Piper M, Lentz R. Prepectoral breast reconstruction: a safe alternative to submuscular prosthetic reconstruction following nipple-sparing mastectomy. Plast Reconstr Surg 2017; 140:432-43.

11. Spear SL, Albino FP, Al-Attar A. Repairing the high-riding nipple with reciprocal transposition flaps. Plast Reconstr Surg 2013;131:687-9. 